C. M. Arndt, R. Schieß1, J. D. Gounder, W. Meier, M. Aigner

Flame stabilization and auto-ignition of pulsed methane jets in a hot coflow: Influence of temperature

Published in Proceedings of the Combustion Institute 34 (2013), pp. 1483-1490

Original publication available at www.elsevier.com

http://www.sciencedirect.com/science/article/pii/S1540748912000831

http://dx.doi.org/10.1016/j.proci.2012.05.082 


\title{
Flame stabilization and auto-ignition of pulsed methane jets in a hot coflow: Influence of temperature
}

\author{
Christoph M. Arndt ${ }^{\mathrm{a}, *}$, Robert Schieß ${ }^{\mathrm{b}}$, James D. Gounder ${ }^{\mathrm{a}}$, Wolfgang Meier ${ }^{\mathrm{a}}$, Manfred Aigner ${ }^{\mathrm{a}}$ \\ ${ }^{a}$ German Aerospace Center (DLR), Institute of Combustion Technology \\ Pfaffenwaldring 38-40, D-70569 Stuttgart, Germany \\ ${ }^{b}$ Karlsruhe Institute of Technology (KIT), Institute of Technical Thermodynamics \\ Kaiserstraße 12, D-76131 Karlsruhe, Germany
}

\begin{abstract}
The auto-ignition of a pulsed methane jet issuing into a coaxial laminar coflow of hot exhaust gas from a lean premixed hydrogen/air flat flame has been studied experimentally by means of high-speed optical diagnostics. The downstream location of the first auto-ignition kernel as well as the stabilization height of the steady-state lifted jet flame and the auto-ignition time were determined by $\mathrm{OH}^{*}$ chemiluminescence (CL) measurements. OH planar laser-induced fluorescence (PLIF) was used to determine further details of the auto-ignition with a higher spatial resolution and increased sensitivity. In order to three-dimensionally reconstruct the ignition kernel location in space and only include ignition kernels in the PLIF processing that first occurred inside the laser light sheet, broadband luminosity imaging from a viewing angle perpendicular to the PLIF and CL measurements was performed. The coflow temperature was varied in the temperature range between $1566 \mathrm{~K}$ and $1810 \mathrm{~K}$ in order to study the influence of the coflow temperature on the autoignition height, auto-ignition time, and on the lift-off height of the steady lifted jet flame. In addition, detailed model simulations were performed to study the influence of temperature and strain on auto-ignition in reacting mixing layers.

Keywords: Auto-ignition, Jet-in-hot-coflow, High-speed diagnostics, Numerical model, Vitiated coflow
\end{abstract}

\section{Introduction}

Auto-ignition of fuel in hot oxidizer is of importance in several technical systems, such as internal combustion engines, gas turbine (GT) combustors employing reheat combustion or flameless combustion

${ }^{*}$ Corresponding author:

E-Mail: christoph.arndt@dlr.de

Fax: +497116862578

Preprint submitted to Proceedings of the Combustion Institute

January 7, 2013 
and scramjets. In GT combustion, auto-ignition can lead to a flame in an undesired region, such as the mixing duct, where fuel is injected into hot air or exhaust gas from a first combustion stage [1, 2]. In swirl flames with a recirculation zone the auto-ignition of mixtures of recirculating hot exhaust gas and fresh gas can contribute to the flame stabilization at the flame root [3].

The physics and chemistry underlying auto-ignition are highly complex and very sensitive to boundary conditions, such as temperature, pressure, strain rate, turbulence level, gas composition, or scalar dissipation [4]. In recent years, direct numerical simulation (DNS) of auto-ignition has contributed substantially to the understanding of auto-ignition [4]. However, for turbulent combustion systems various aspects of autoignition are still not well enough understood and the computation of mixing and chemistry under those conditions remains challenging [5].

With the development of innovative high-speed cameras and laser systems [6], the time-resolved study of auto-ignition processes is accessible experimentally. Optical and laser-based investigations have been performed on several configurations of auto-ignition in transient injection processes. Sadanandan et al. [7] studied the ignition of hydrogen/air mixtures by a jet of hot exhaust gases and Bruneaux [8] examined the injection of a diesel surrogate jet into hot air at elevated pressure. Fast et al. [9] and Haessler et al. [10] studied the auto-ignition after the pulsed injection of dimethyl ether (DME) into a constant pressure atmosphere at elevated temperature. Oldenhof et al. [11] investigated the pulsed injection of natural gas into hot exhaust gas of a hydrogen/air flame with Reynolds numbers of 4100 and 8800 . One difficulty in these experiments lay in the accomplishment of well-defined boundary conditions, for example, providing a homogeneous gas distribution within the coflow (or ambient gas) or knowledge of the temperature of the fuel jet. Arndt et al. [12] studied the pulsed injection of a turbulent methane jet into the hot exhaust gas of a hydrogen/air flame and the subsequent auto-ignition in a simple configuration with defined boundary conditions.

The present study focuses on the influence of the coflow temperature on auto-ignition and subsequent flame stabilization of a pulsed methane jet, which is injected into the hot exhaust products of a lean premixed hydrogen/air flat flame at atmospheric pressure. The setup is similar to other jet-in-hot-coflow burners [13-15]. However, previous experimental [13-16] and numerical [13, 17-20] studies focused on the flame stabilization mechanism of the stably burning lifted jet flame at steady-state conditions (jet-in-hot-coflow). 
From these studies it was concluded that the lifted flame is stabilized by auto-ignition.

The focus of the present study lies on the initial auto-ignition of a pulsed methane jet, the subsequent flame stabilization and the influence of the coflow temperature on those phenomena. Simultaneous $\mathrm{OH}$ planar laser-induced fluorescence, $\mathrm{OH}^{*}$ chemiluminescence and broadband flame luminosity imaging have been applied at a sustained repetition rate of $5 \mathrm{kHz}$ to study the spatial and temporal onset of auto-ignition kernels, and the development of the steady-state lifted jet flame. Model simulations of auto-ignition were performed to gain insight into the role of temperature and strain rate onto auto-ignition and to assist the interpretation of experimental results.

\section{Experiment and diagnostics}

Parts of the experiment as well as the burner and the data evaluation process have been described in the literature before $[12,21,22]$, so only the key parameters of the experimental setup and data analysis are presented here.

\subsection{Burner}

A schematic of the DLR Jet-in-Hot-Coflow (DLR JHC) burner is shown in Fig. 1. A lean premixed hydrogen/air flame was stabilized on a quadratic $\left(75\right.$ by $\left.75 \mathrm{~mm}^{2}\right)$ bronze sinter matrix. The flame was confined by a square 80 by $80 \mathrm{~mm}^{2}$ combustion chamber with a height of $120 \mathrm{~mm}$ to prevent any disturbance of the flow. The combustion chamber was equipped with four quartz windows held by steel posts in each corner. The nozzle was a stainless steel tube (inner diameter $2 \mathrm{~mm}$, outer diameter $3 \mathrm{~mm}$ ). The tip of the nozzle was $8 \mathrm{~mm}$ above the matrix. Pulsed methane was injected into the nozzle through a 2/2 way spider valve (Staiger VA 204-5), located approximately $250 \mathrm{~mm}$ below the tip of the nozzle.

The operating conditions are summarized in Tab. 1. The flow rates were controlled with Brooks MFC 5850 mass flow controllers and monitored with calibration standard coriolis flow meters (Siemens Sietrans Mass 2100) with an accuracy of $1.5 \%$ [24]. The accuracy of the calculated adiabatic flame temperature $\left(T_{a d}\right)$ was estimated by assuming the highest uncertainty of the flow rates and calculating $T_{a d}$ for these cases. It was on the order of $\pm 2 \%$. Previous measurements in a similar configuration have shown that the exhaust gas temperature stays very close to $T_{a d}$ if heat loss to the matrix is minimized [25]. To meet this criterion the velocities of the unreacted gas were chosen to exceed $0.7 \mathrm{~m} \mathrm{~s}^{-1}$. The velocity of the coflow of the hot 
combustion products was held constant at $4 \mathrm{~m} \mathrm{~s}^{-1}$. A coriolis meter in line with the $\mathrm{CH}_{4}$-injection system was used to calculate the bulk flow velocity and the exit Reynolds number. The exit velocity for the steadystate jet was $100 \mathrm{~m} \mathrm{~s}^{-1}$ and the Reynolds number was 13,000 for all examined cases. The stagnation pressure in front of the valve between pulses was 2 bar.

\subsection{Planar laser-induced fluorescence (PLIF)}

Fig. 2 shows the experimental setup. A frequency doubled dye laser (Sirah Cobra Stretch HRR, pulse energy $0.1 \mathrm{~mJ}$ at $283.2 \mathrm{~nm}$ ), was pumped by a diode-pumped solid-state laser (Edgewave IS8II-DE) at $5 \mathrm{kHz}$ repetition rate. The dye laser was tuned to match the $\mathrm{Q}_{1}(7)$ transition in the $\mathrm{A}-\mathrm{X}(1,0)$ band of $\mathrm{OH}$. The laser beam was formed into a light sheet with a two-stage cylindrical telescope and focused into the test section with a third cylindrical lens. The resulting sheet was $44 \mathrm{~mm}$ in height with a beam waist of $0.4 \mathrm{~mm}$. The fluorescence signal was detected with an intensified high-speed CMOS camera (LaVision HSS 5 with LaVision HS-IRO) with a fast UV lens (Cerco). Elastic scattering of the laser light and broadband flame luminosity were suppressed using a high-transmission bandpass filter (T>80\% at $310 \mathrm{~nm}$, Laser Components) and a short (200 ns) intensifier gate. Non-uniformities in the sheet profile were corrected in a postprocessing step using an average of 1000 images of the fluorescence of a uniform acetone vapor distribution in the combustion chamber. $\mathrm{OH}$ is formed in the reaction layer predominantly via $\mathrm{H}+\mathrm{O}_{2} \rightarrow \mathrm{OH}+\mathrm{O}$ and $\mathrm{O}+\mathrm{H}_{2} \rightarrow \mathrm{OH}+\mathrm{H}$ [27]. At chemical equilibrium the $\mathrm{OH}$ concentration increases with temperature and lies above the LIF detection limit above $\mathrm{T} \approx 1500 \mathrm{~K}$.

\subsection{Chemiluminescence $(C L)$ and broadband flame luminosity imaging}

Electronically excited $\mathrm{OH}\left(\right.$ termed $\mathrm{OH}^{*}$ ) in hydrocarbon flames is formed in the reaction layer via $\mathrm{CH}+\mathrm{O}_{2} \rightarrow \mathrm{OH}^{*}+\mathrm{CO}, \mathrm{HCO}+\mathrm{O} \rightarrow \mathrm{OH}^{*}+\mathrm{CO}$ and $\mathrm{O}+\mathrm{H}+\mathrm{M}=\mathrm{OH}^{*}+\mathrm{M}[28,29]$. The dominant degradation pathway is via collisional quenching, but a small amount also involves the emission of light $\lambda \approx 310 \mathrm{~nm}$ via $O H^{*} \rightarrow O H+h v$.

Imaging of $\mathrm{OH}^{*} \mathrm{CL}$ was performed using an identical high-speed camera and intensifier setup as for the PLIF, but mounted on the opposite side of the burner.

Broadband flame luminosity was recorded with an additional high-speed CMOS camera (LaVision HSS 6), 
looking along the axis of the laser light sheet. This enabled the identification of auto-ignition events where the first ignition kernel was inside the laser light sheet.

\subsection{Measurement procedure}

Before the measurements, the matrix burner was run for at least $10 \mathrm{~min}$ to achieve thermal equilibrium. Then, a trigger started a fixed-length recording of the cameras, and $2 \mathrm{~ms}$ later the solenoid valve received a trigger and started the pulsed jet. This procedure was repeated 80 times with a rate of $0.5 \mathrm{~Hz}$, corresponding to approximately 65 times the coflow advection time ( $\mathrm{v}_{\text {coflow }} /$ combustion chamber height) for $\mathrm{CH}_{4}$ injection durations of $55 \mathrm{~ms}$. This enabled the flowfield to regain the stationary state without jet in between runs. After 80 recording cycles the images were downloaded to the measurement computer and the sequence was repeated. Two repetitions, resulting in a total of 160 runs, were conducted for each flame condition (except for Flame 1, where only 80 runs were performed).

\section{Data reduction and analysis}

After background correction and filtering, the $\mathrm{OH}^{*} \mathrm{CL}$ images were converted to black and white by using a threshold. Noise from the image intensifier (visible as spots in the $\mathrm{b} / \mathrm{w}$ image) was filtered out by defining a minimum size for the auto-ignition kernels. All spots with a smaller size were defined as noise. The auto-ignition height $h_{i g n}$ was defined as the lower edge of the first detected auto-ignition kernel. In case of several auto-ignition kernels, the position of the kernel with the lowest axial position was used. The autoignition time $\tau_{i g n}$ is defined here as the time span between the jet exiting the fuel nozzle and the appearance of the first auto-ignition kernel that was observed by $\mathrm{OH}^{*} \mathrm{CL}$. The jet development was measured with a high-speed Schlieren system. In the near-field the jet development was reproducible and very similar for all operating cases. The jet exited the nozzle $2.9( \pm 0.2) \mathrm{ms}$ after the trigger for the valve. The measurement error of the auto-ignition height due to image slip was estimated by calculating the flame kernel convection during image exposure and between frames. In the CL measurements, the image slip was $0.2 \mathrm{~mm}$ during exposure and $1 \mathrm{~mm}$ between frames, for the broadband luminosity it was $1 \mathrm{~mm}$ both inframe and interframe. 


\section{Numerical modeling of the auto-ignition process}

As a guideline for the interpretation of the experimental findings, numerical model simulations were performed. Auto-ignition scenarios in counterflow-configurations were simulated, where hot exhaust gas from $\mathrm{H}_{2} /$ air mixtures (corresponding to mixture fraction $f=0$ ) flowed versus methane (corresponding to $f=1$ ). This approach represents a microscopic viewpoint, where an ignition in a laminar mixing layer between methane jet and surrounding hot coflow is studied.

Temperature, pressure and composition of the inlet streams were set to the nominal values of the experiment. For the exhaust gas, adiabatic equilibrium for a given hydrogen/air mixture was assumed. Simulations were performed for all coflow conditions studied in the experiment (cf. Tab. 1). To assess the influence of coflow temperature, simulations with this temperature set $30 \mathrm{~K}$ below the adiabatic value were performed, and the influence of the flow field on auto-ignition was investigated by repeated simulations with varied values of the strain rate. Here, a mixture-averaged transport model was used (equal diffusivities of all species, Le $=1$ ). For comparison, the simulations were repeated with a detailed transport model, including the Soreteffect. The influence of the transport model on ignition delays was negligible.

The simulations were initialized with sigmoidal profiles of temperature and species, resulting from inert mixing of hot coflow and methane jet, with steep gradients of the scalars (e.g., $\left.(\mathrm{d} T / \mathrm{d} z)_{\max }=2 \times 10^{7} \mathrm{~K} \mathrm{~m}^{-1}\right)$, to mimic the initial steep gradients at the jet boundary when it exits the nozzle.

The conservation equations for these conditions were solved on a one-dimensional spatial domain by a time-accurate unsteady approach, using a detailed description of chemical reactions (mechanism for the oxidation of methane) and of transport terms [26].

In addition, to determine ignition delay times in homogeneous mixtures of methane and exhaust gas, homogeneous reactor calculations were performed. These represent the limiting case of ignition without any interference by transport and help to better understand the influence of transport processes on ignition delay times. 


\section{Results and discussion}

\subsection{Temperature influence on auto-ignition and flame stabilization}

The influence of the coflow temperature $T_{\text {coflow }}$ on the steady jet flame is shown in Fig. 3, where the averaged $\mathrm{OH}^{*} \mathrm{CL}$ for the lifted jet flame for each of the coflow conditions is displayed. The averages were computed on a basis of 3400 consecutively recorded frames. The difference in $T_{\text {coflow }}$ from one flame setting to the next (see Tab. 1) is approximately $40 \mathrm{~K}$. The reduction of the lift-off height with increasing $T_{\text {coflow }}$ can clearly be seen. Interestingly, Flames $1-3$ (i.e. flames with $T_{\text {coflow }}$ below $\approx 1700 \mathrm{~K}$ ) exhibit a larger reduction than Flames 5-7.

Figure 4 shows the influence of $T_{\text {coflow }}$ on the measured auto-ignition time $\tau_{\text {ign }}$. It was in the range $0.9 \mathrm{~ms}$ $>\tau_{\text {ign }}>3.5 \mathrm{~ms}$ for all examined coflow conditions and decreased, as expected, with increasing coflow temperature. For Flame 1, the average auto-ignition time was $2.80 \mathrm{~ms}$ with a standard deviation of $0.19 \mathrm{~ms}$, whereas for Flame 7 it was $1.09 \mathrm{~ms}$ with a standard deviation of $0.05 \mathrm{~ms}$ (cf. Tab. 2). The shift to longer $\tau_{\text {ign }}$ for lower $T_{\text {coflow }}$ is explained by an increase in the ignition delay time, as discussed below. Ignition delay time in this context means the theoretical onset time of auto-ignition without any influence of the transient flow-field evolution of the jet and differs from $\tau_{i g n}$.

In Fig. 5 the temperature dependence of the auto-ignition height $h_{i g n}$ and the average lift-off height $L O H_{\text {avg }}$ of the subsequent lifted jet flames is shown. $h_{i g n}$ shifts downstream with decreasing coflow temperature. The same behavior is observed for $L O H_{a v g}$, but with a steeper slope than for $h_{i g n}$. $L O H_{a v g}$ was determined by measuring the average lift-off height of the steady-state lifted jet flame for each of the individual ignition events (by taking the average lift-off height over a period of $10 \mathrm{~ms}$ ). For Flame 1 the mean auto-ignition height is slightly smaller than the mean lift-off height. This indicates that auto-ignition presents a significant or even the dominant contribution to flame stabilization. For all other flames it was vice versa, in other words, after auto-ignition the flame moved slightly upstream. The question arises whether this shift is due to flame propagation or another mechanism, like the formation of secondary ignition kernels that occur later in time at a lower axial location. For the steady burning Flame 3 it was frequently observed that auto-ignition kernels appeared below the mean lift-off height, propagated downstream and merged with the flame base [12]. This observation backs the interpretation that the flame is at least partially stabilized by auto-ignition. The upstream shift of the flame after auto-ignition might be a result of the influence of thermal expansion 
and increase of viscosity at the flame base on the approaching unburned gas flow.

\subsection{Influence of strain and scalar dissipation}

It is well-known that the auto-ignition probability depends significantly on the local mixture fraction and strain rate (or scalar dissipation rate) [4]. These quantities could not be measured in the current experiment. However, to assess their influence on auto-ignition, simulations of a counterflow arrangement were performed. Figure 6 shows the computed ignition delay times $\tau_{i d}$ and their dependence on the strain-rate $G$. The values given for $G$ here refer to the location and time where auto-ignition first occurred, and $\tau_{i d}$ was defined as the time when the $\mathrm{OH}$ concentration rises to twice the $\mathrm{OH}$ concentration of the coflow. This is approximately the sensitivity of the PLIF system, as will be discussed below. $\tau_{i d}$ cannot be compared directly to the experiment, because of the simplified treatment of the flow field in the simulations. The trends of both the experimental and calculated results however, can be compared and the influence of strain can be evaluated. The measured and simulated ignition delay times show similar slopes, but $\tau_{\text {ign(exp.) }}$ tends to be larger than $\tau_{i d(s i m .)}$. The absolute difference between the ignition delay times for the hottest and coldest coflow is higher in the experiment, i.e. $\Delta \tau_{i d}=0.7 \mathrm{~ms}$ for the simulations (for a small strain rate) and $\Delta \tau_{i g n}=$ $1.7 \mathrm{~ms}$ for the experiment. This difference can be explained by the higher influence of strain on the ignition time for lower temperatures. In comparison, also the ignition delay time for a homogeneous reactor at the fastest igniting mixture fraction is shown in Fig. 6. It is evident, that for the homogeneous reactor, $\tau_{i d}$ is significantly smaller than in the detailed model simulation including transport, even for very small $G$, since even with no strain transport processes affect the chemistry.

The simulations show that, for small strain rates, the ignition delay time is hardly influenced by the strain rate. With increasing strain, the ignition delay becomes significantly influenced by the strain and finally the strain inhibits auto-ignition completely. The critical strain rate $G_{c r i t}$ above which no auto-ignition occurs increases with coflow temperature; for the coflow temperatures studied here, $G_{c r i t}$ ranges between 1000 and $5000 \mathrm{~s}^{-1}$. The influence of strain rate is strongly temperature dependent, i.e. the minimal strain rate that influences the ignition delay becomes lower for decreasing coflow temperatures. Also, the ignition delay becomes more sensitive to strain at lower temperatures. The difference in absolute values of the ignition delay between the experiment and the simulations can possibly be explained by the high expected strain rates at the jet boundary and thus a high influence of strain on $\tau_{i g n}$. Near the nozzle, the turbulent jet exhibits a 
smooth, laminar-like boundary with high scalar dissipation rates in the boundary layer, as can be seen from Schlieren measurements [12]. Further downstream, the boundary layer becomes corrugated and the scalar dissipation rate and strain rate vary significantly. The relatively low scalar dissipation rates in the bulges of the boundary layer favor auto-ignition in those locations. This behavior was observed in theoretical and experimental studies $[4,12]$ and is also demonstrated in Fig. 7, which will be discussed below. Thus, the auto-ignition time is at least partially controlled by the flow field.

The minimum axial location of observed auto-ignition for a given temperature (see Fig. 5) also shows a temperature dependence, which flattens out for higher temperatures. This suggests that, below a critical downstream location, strain becomes too high to allow auto-ignition, independent of the coflow temperature. Similarly, for the higher coflow temperatures no auto-ignition kernels were observed below the flame base, which also rules out the formation of secondary ignition kernels at lower axial locations. This assumption, however, needs further evaluation from additional experiments.

\subsection{Most reactive mixture}

Due to the difference between the initial temperatures of methane and the oxidizer auto-ignition is expected to occur at very lean mixtures. For a homogeneous reactor, the mixture fraction with smallest ignition delay has been calculated and is termed $f_{m r}$ here. $f_{m r}$ is about $1 \%$ of the stoichiometric mixture fraction (see Table 1) with values of $f_{m r} \approx 10^{-4}$. This means that auto-ignition is expected at the outmost periphery of the fuel jet. In this context the question arises whether the onset of auto-ignition can be captured by the diagnostic methods applied here. In previous measurements it was observed that OH PLIF is more sensitive than chemiluminescence imaging for the detection of the onset of auto-ignition, at least for the conditions prevailing in this setup [12, 22]. Figure 7 shows an OH PLIF image sequence of an auto-ignition event (coflow Flame 2) where the first ignition occurred within the PLIF laser sheet, as was determined from the camera recording the broadband luminosity. In the first frame, the equilibrium $\mathrm{OH}$ from the coflow can be seen as faint blue signal left and right of the cold inflowing methane jet (black region in the center of the frame). The composition of the coflow is known (see Tab. 1), with the $\mathrm{OH}$ mole fraction being on the order of $2 \times 10^{-4}$. The auto-ignition kernel that is observed in the subsequent frame at $(x / z)(-8 \mathrm{~mm} / 26 \mathrm{~mm})$ forms in a bulge of the inflowing jet, where scalar dissipation and strain rate are expected to be low $[4,12]$. 
Here, the PLIF signal is approximately double the signal of the coflow, corresponding to a mole fraction of approximately $4 \times 10^{-4}$. The PLIF signal does, however, not only depend on the mole fraction of $\mathrm{OH}$, but also on other parameters such as temperature and composition (via quenching, ground state population, collisional effects), so these numbers only give an estimation of the system sensitivity. But factors (besides $\mathrm{OH}$ concentration) influencing the LIF signal (temperature, quenching and collisional broadening) hardly change between $f \approx 0$ and $f \approx 0.3$, which is the relevant range for ignition. The same sensitivity is assumed for all coflow conditions, since the PLIF signal from the equilibrium $\mathrm{OH}$ can always be well distinguished from the region of the inflowing cold methane jet. Therefore, auto-ignition can be detected in very lean mixtures of the flow, close to the fastest igniting mixture fraction $f_{m r}$. It is to note that the sensitivity of the $\mathrm{OH}^{*}$ chemiluminescence system was not evaluated and is expected to be lower than that of the PLIF system. Typically, the auto-ignition could be observed in the $\mathrm{OH}^{*} \mathrm{CL} 1-2$ frames (corresponding to $0.2-$ $0.4 \mathrm{~ms}$ ) later than in the PLIF frames. The location of maximum $\mathrm{OH}^{*} \mathrm{CL}$ and $\mathrm{OH}$ LIF signal do not necessarily overlap. In the simulations shown, $\mathrm{OH}^{*} \mathrm{CL}$ reactions were not included. The accuracy of the currently available reaction mechanisms for chemiluminescent species under the complex conditions of this experiment is uncertain. Qualitatively, however, the incorporation of reactions for $\mathrm{OH}^{*}$ from Kathrotia et al. [29] into our mechanism revealed that the locations of maxima of $\mathrm{OH}$ and $\mathrm{OH}^{*}$ differ in space and time.

\section{Conclusions}

High-speed $\mathrm{OH}^{*}$ chemiluminescence and $\mathrm{OH}$ planar laser-induced fluorescence (PLIF) measurements have been performed on the auto-ignition of a pulsed methane jet issued into a vitiated coflow. The exhaust gas of a lean premixed hydrogen/air flame provided the coflow with temperatures between $1566 \mathrm{~K}$ and $1810 \mathrm{~K}$ with an oxygen content between 10.2 and $7.7 \mathrm{~mol} \%$. The height of the first auto-ignition kernel, the auto-ignition time and the lift-off height of the corresponding steady-state jet flame in dependence on the coflow temperature have been studied. The experimental results have been complemented by detailed model simulations.

For the dependence of the auto-ignition time on the coflow temperature, the experiments and calculations exhibited the same trends, however, the calculated ignition times tended to be shorter. This was attributed to the influence of strain, which is expected to be very high in the lower start regions of the jet, where the 
boundary layer is quite smooth without corrugations. The appearance of corrugations (regions with locally lower strain) further downstream increases the probability of auto-ignition. This was confirmed experimentally by the preferred occurrence of auto-ignition sites in bulges and is also known from theoretical studies. For the Flames 2-7, it was observed that the mean lift-off height of the steady burning flames was slightly smaller than the height at which first auto-ignition kernels appeared. This behavior could not be explained but it is conjectured that the thermal expansion and increase of viscosity which come along with the establishment of the flame base might reduce the strain in the approaching flow of unburned fuel/oxidizer mixtures. Here, high-speed flow-field measurements would ideally complement the data set.

The calculation of a homogeneous reactor showed that the fastest igniting mixtures for this configuration are very lean at about $1 \%$ of the stoichiometric mixture fraction. Thus, auto-ignition is expected to occur at the outer edge of the methane jet, where the physical and chemical conditions are dominated by the coflow. The comparison of the OH PLIF signals with the calculated $\mathrm{OH}$ mole fractions revealed that the high-speed PLIF system is capable of detecting the very onset of auto-ignition close to the fastest igniting mixture fraction.

The presented setup has proven to be well-suited for auto-ignition studies of fuel jets in hot coflows. Further experimental efforts will target at higher repetition rates for the imaging diagnostics and the application of further techniques like Rayleigh scattering for the determination of the mixture fraction and possibly particle image velocimetry for the study of the flow-field.

\section{Acknowledgments}

The authors thank Isaac Boxx and Adam Steinberg for their help in setting up the experiment. Financial support within the DLR project IVTAS is gratefully acknowledged.

\section{References}

[1] F. Güthe, J. Hellat, P. Flohr, J. Eng. Gas Turbines Power 131 (2009) 021503.

[2] J. Fleck, P. Griebel, A.M. Steinberg, M. Stöhr, M. Aigner, J. Eng. Gas Turbines Power 134 (2012) 041502.

[3] I. Boxx, M. Stöhr, C. Carter, W. Meier, Combust. Flame 157 (2010) 1510-1525.

[4] E. Mastorakos, Prog. Energy Combust. Sci. 35 (2009) 57-97.

[5] E.M. Ivanova, B.E. Noll, M. Aigner, J. Eng. Gas Turbines Power 133 (2011) 021505. 
[6] B. Böhm, C. Heeger, R.L. Gordon, A. Dreizler, Flow, Turbulence, Combust. 86 (2011) 313-341.

[7] R. Sadanandan, D. Markus, R. Schieß1, U. Maas, J. Olofsson, H. Seyfried, M. Richter, M. Aldén, Proc. Combust. Inst. 31 (2007) 719-726.

[8] G. Bruneaux, Oil Gas Sci. Technol. 63 (2008) 461-477.

[9] G. Fast, D. Kuhn, A.G. Class, U. Maas, Combust. Flame 156 (2009) 200-213.

[10] H. Haessler, H. Bockhorn, C. Pfeifer, D. Kuhn, Flow Turbul. Combust. (2012), in print. doi: 10.1007/s10494-011-9374-8.

[11] E. Oldenhof, M.J. Tummers, E.H. van Veen, D.J.E.M. Roekaerts, Combust. Flame 159 (2012), 697-706.

[12] C.M. Arndt, J.D. Gounder, W. Meier, M. Aigner, Appl. Phys. B (2012), in print. doi: 10.1007/s00340-012-4945-5.

[13] R. Cabra, J.-Y. Chen, R.W. Dibble, A.N. Karpetis, R.S. Barlow, Combust. Flame 143 (2005) 491-506.

[14] E. Oldenhof, M.J. Tummers, E.H. van Veen, D.J.E.M. Roekaerts, Combust. Flame 157 (2010) 1167-1178.

[15] B.B. Dally, A.N. Kerpetis, R.S. Barlow, Proc. Combust. Inst. 29 (2003) 1147-1154.

[16] R.L. Gordon, A.R. Masri, E. Mastorakos, Combust. Flame 155 (2008) 181-195.

[17] F.C. Christo, B.B. Dally, Combust. Flame 142 (2005) 117-129.

[18] R.L. Gordon, A.R. Masri, S.B. Pope, G.M. Goldin, Combust. Theor. Model. 11 (2007) 351-376.

[19] M. Ihme, Y.C. See, Combust. Flame 157 (2010) 1850-1862.

[20] A. De, E. Oldenhof, P. Sathia, D. Roekaerts, Flow, Turbulence, Combust. 87 (2011) 537-567.

[21] C.M. Arndt, J.D. Gounder, I.G. Boxx, K. Marr, W. Meier, M. Aigner, in: Proc. 5th Europ. Combust. Meeting, 2011, Paper 28.

[22] W. Meier, C.M. Arndt, J. Gounder, I. Boxx, K. Marr, in: Proc. 23rd ICDERS, 2011, Paper 90.

[23] C. Morley, Gaseq - a chemical equilibrium program for windows.

[24] Manufacturer information.

[25] S. Prucker, W. Meier, W. Stricker, Rev. Sci. Instrum. 65 (1994) 2908-2911.

[26] G. Stahl, J. Warnatz, Combust. Flame 85 (1991) 285-299.

[27] J. Warnatz, U. Maas, R.W. Dibble, Combustion - Physical and Chemical Fundamentals, Modeling und Simulation, Experiments, Pollutant Formation, Springer, Berlin, Germany, 2006

[28] L.C. Haber, U. Vandsburger, Combust. Sci. Technol. 175 (2003) 1859-1891.

[29] T. Kathrotia, M. Fikri, M. Bozkurt, M. Harmann, U. Riedel, C. Schulz, Combust. Flame 157 (2010) 1261-1273. 


\section{Tables}

\begin{tabular}{|c|c|c|c|c|c|c|c|c|c|}
\hline \multirow[b]{2}{*}{ Flame } & \multicolumn{2}{|c|}{ Flow Rates [g/min] } & \multirow[b]{2}{*}{$\phi$} & \multirow[b]{2}{*}{$\mathrm{T}_{\mathrm{ad}}[\mathrm{K}]$} & \multicolumn{4}{|c|}{ Exhaust Gas Composition [mol \%] } & \multirow[b]{2}{*}{$f_{s t}$} \\
\hline & Air & $\mathrm{H}_{2}$ & & & $\mathrm{O}_{2}$ & $\mathrm{~N}_{2}$ & $\mathrm{H}_{2} \mathrm{O}$ & $\mathrm{OH}$ & \\
\hline 1 & 278 & 3.77 & 0.466 & 1566 & 10.21 & 71.96 & 17.82 & 0.0163 & 0.0306 \\
\hline 2 & 270 & 3.81 & 0.485 & 1607 & 9.81 & 71.69 & 18.47 & 0.0225 & 0.0295 \\
\hline 3 & 262 & 3.85 & 0.505 & 1648 & 9.39 & 71.42 & 19.16 & 0.0308 & 0.0284 \\
\hline 4 & 254 & 3.90 & 0.527 & 1694 & 8.93 & 71.12 & 19.90 & 0.0424 & 0.0271 \\
\hline 5 & 248 & 3.94 & 0.548 & 1736 & 8.50 & 70.84 & 20.61 & 0.0562 & 0.0258 \\
\hline 6 & 241 & 3.98 & 0.567 & 1773 & 8.11 & 70.58 & 21.24 & 0.0714 & 0.0247 \\
\hline 7 & 235 & 4.01 & 0.586 & 1810 & 7.72 & 70.34 & 21.86 & 0.0894 & 0.0236 \\
\hline
\end{tabular}

Table 1: Operating conditions for the matrix burner for the vitiated coflow with calculated adiabatic flame temperatures $\mathrm{T}_{\mathrm{ad}}$ and exhaust gas compositions (for a fresh gas temperature of $290 \mathrm{~K}$ ) [23]. $f_{s t}$ is the stoichiometric mixture fraction for $\mathrm{CH}_{4} /$ exhaust gas mixtures. 


\begin{tabular}{lrrr}
\hline Flame & $\left\langle\tau_{i g n}>\right.$ & $\left\langle h_{\text {ign }}\right\rangle$ & $<L O H>$ \\
& {$[\mathrm{ms}]$} & $/ \mathrm{d}$ & $/ \mathrm{d}$ \\
\hline 1 & $2.80(0.19)$ & $18.97(2.33)$ & $19.02(1.20)$ \\
2 & $2.19(0.13)$ & $15.17(2.46)$ & $13.87(0.80)$ \\
3 & $1.74(0.11)$ & $11.83(2.57)$ & $9.67(0.51)$ \\
4 & $1.45(0.09)$ & $9.03(1.83)$ & $6.43(0.35)$ \\
5 & $1.26(0.08)$ & $7.31(1.14)$ & $4.81(0.26)$ \\
6 & $1.13(0.07)$ & $6.72(1.21)$ & $3.85(0.24)$ \\
7 & $1.09(0.05)$ & $5.91(0.69)$ & $2.76(0.10)$ \\
\hline
\end{tabular}

Table 2: Summary of the experimental results. $\tau_{i g n}$ is the auto-ignition time, $L O H_{\text {avg }}$ is the lift-off height and $h_{i g n}$ is the height of the first observed auto-ignition kernel. $\mathrm{d}$ is the nozzle diameter. In brackets are the standard deviations of the measured values. 


\section{Figures}

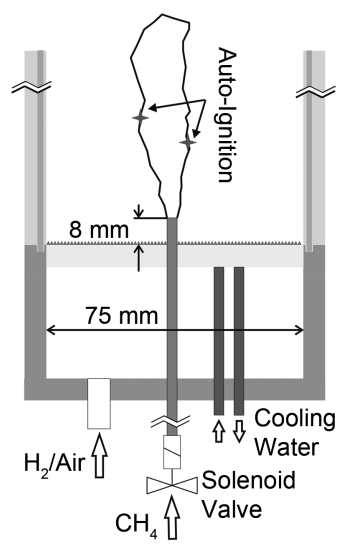

Figure 1: Schematic drawing of the DLR Jet-in-Hot-Coflow burner with the matrix burner and the injector system.

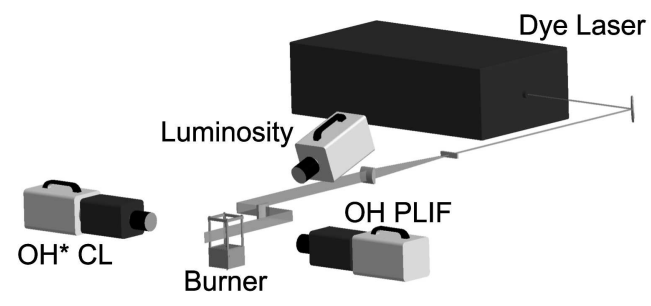

Figure 2: Experimental setup for the simultaneous OH PLIF, OH* chemiluminescence and broadband luminosity measurements.

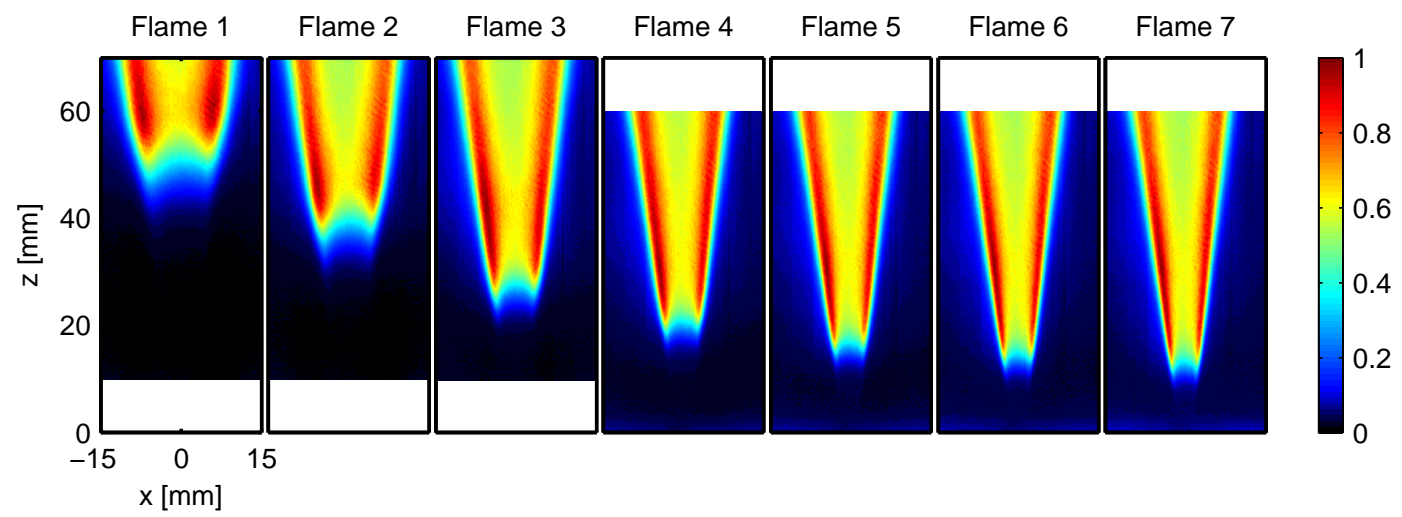

Figure 3: Normalized average chemiluminescence of the steady-state lifted jet flame for the different coflow conditions. 


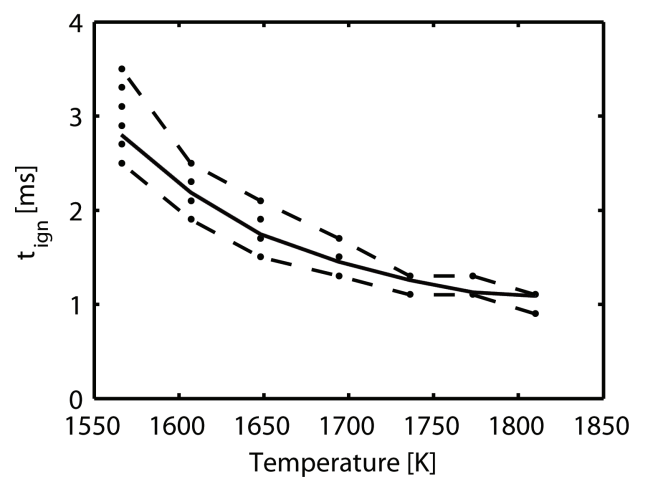

Figure 4: Influence of coflow temperature on the measured auto-ignition time $\tau_{i g n}$. Symbols are the measured data points, the solid line is the mean value and the dotted lines represent the minimum and maximum values.

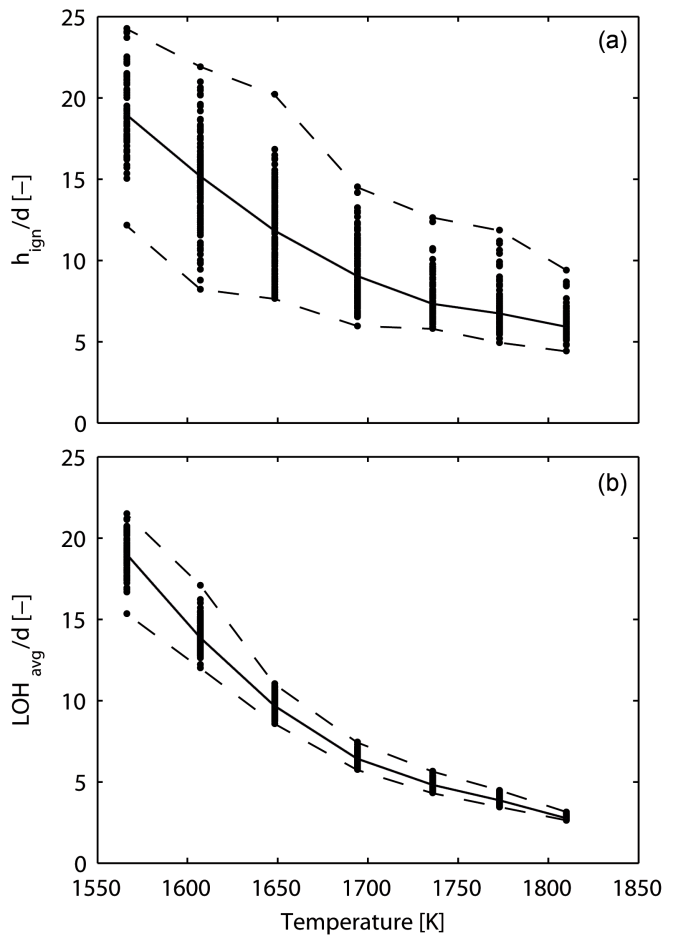

Figure 5: Influence of coflow temperature on (a) the measured average auto-ignition height $h_{i g n}$ and (b) the mean stabilization height of the lifted jet flame $\mathrm{LOH}_{\text {avg }}$. Symbols are the measured data points, the solid line is the mean value and the dotted lines represent the minimum and maximum values. 


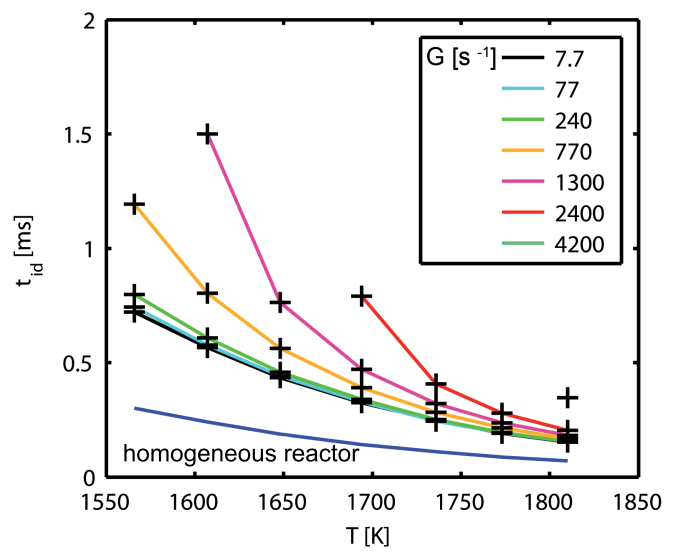

Figure 6: Calculated ignition delay times with a homogeneous reactor at the minimum ignition delay mixture fraction $f_{m r}$ and for counterflow diffusion flames with varying strain rate $G$.

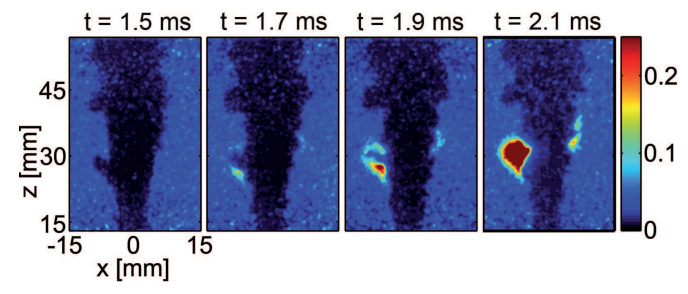

Figure 7: Sample image sequence of an auto-ignition event recorded with high-speed PLIF to demonstrate the $\mathrm{OH}$ evolution during an auto-ignition event. The colorbar is normalized to the maximum signal intensity of the image series. 